\title{
Anglo-Saxon England
}

\section{Volume 45}

Anglo-Saxon England is recognised universally as the foremost regular publication in its field. It is the only one which consistently embraces all the main aspects of Anglo-Saxon history and culture - linguistic, literary, textual, palaeographic, religious, intellectual, historical, archaeological and artistic - and which promotes the more unusual interests - musical, medicinal or educational, for example.

\section{CAMBRIDGE UNIVERSITY PRESS www.cambridge.org/core}

